\title{
Characterization of milli- and microflow reactors: mixing efficiency and residence time distribution
}

\author{
Sven R. L. Gobert ${ }^{\mathrm{a}}$, Simon Kuhn ${ }^{\mathrm{b}}$, Leen Braeken ${ }^{\mathrm{a}, \mathrm{b}}$, Leen C. J. Thomassen ${ }^{\mathrm{a}, \mathrm{b}}$ \\ ${ }^{a}$ KU Leuven, Faculty of Industrial Engineering, Lab4U; Agoralaan building B box 8, 3590 Diepenbeek BELGIUM \\ ${ }^{\mathrm{b}}$ KU Leuven, Department of Chemical Engineering; Celestijnenlaan 200F, 3001 Leuven BELGIUM
}

\begin{abstract}
KEYWORDS. milli-and microflow reactor, Villermaux-Dushman, micromixing time, macromixing, residence time distribution.
\end{abstract}

\begin{abstract}
The increasing academic and industrial interest in flow chemistry resulted in the development of various micro- and milliflow reactors for a wide range of reactions. Owing to this variety in flow reactors, it is vital to select the correct type benefitting the considered chemical reaction. This decision can be based on two fundamental reactor characterization techniques, namely the residence time distribution (RTD) and the Villermaux-Dushman protocol. The first technique highlights deviations from ideal plug flow, while the latter is a reaction based characterization technique to quantify the efficiency of micromixing. This paper compares the performance of classical tube reactors with internal diameters ranging from 0.4 to $4.8 \mathrm{~mm}$ and commercial chip reactors from Little Things Factory and Chemtrix (KiloFlow and Labtrix) are characterized and serves as an aid for reaction selection dependent on the kinetics of the studied reaction. The suitability of a reactor for very fast reactions (reaction half-life < 1 s) or fast reactions (reaction time $1 \mathrm{~s}$ to $10 \mathrm{~min}$ ) is determined from this characterization.
\end{abstract}

\section{INTRODUCTION}

The advantages of flow reactors are well known and include improved heat transfer, mixing, accessibility of novel process conditions (extreme pressures and temperatures) and safer operation. ${ }^{1,2}$ The increased interest in flow reactors has spawned a wide range of micro and milli-flow devices., Micro and milli-flow reactors are characterized by channel dimensions below $1 \mathrm{~mm}$ and around a few millimeters respectively. ${ }^{2,5,6}$ Choosing the optimum reactor to execute a desired reaction requires matching its characteristics to the reaction kinetics. Mass and heat transfer properties are the most important parameters in the reactor performance. This study focusses on the characterization of mass transfer, through micromixing and axial dispersion. Dispersion is caused by fluctuations in the velocity profile of the fluid passing through the reactor channel due to molecular and turbulent diffusion. ${ }^{7}$ It indicates the displacement of material in the direction of the flow and results in fluid elements exiting the reactor at different residence times. This distribution of residence time influences the conversion of each fluid element and in turn the final conversion at the reactor exit. The second characteristic, micromixing, is defined as mixing on molecular scale. ${ }^{8}$ It is considered fast when the mixing time $\left(t_{m}\right)$ is shorter than the reaction time $\left(t_{r}\right)$. When $t_{r}<t_{m}$, mixing is slow, which results in concentration gradients, lowering reactor performance and increasing byproduct formation. ${ }^{8}$ The importance of each of these characteristics for the reactor depends on the type of reaction, which can be classified based on the kinetics of the reaction. ${ }^{9}$ Type A reactions include very fast reactions, with a reaction half-life less than $1 \mathrm{~s}$. They benefit from fast initial mixing. ${ }^{8}$ Type $B$ reactions are fast with reaction rates between $1 \mathrm{~s}$ and
10 min, which makes them kinetically controlled in reactors with high micromixing efficiencies. Type $\mathrm{C}$ reactions are slow with reaction rates larger than $10 \mathrm{~min}$. This last category is less suited for flow, the main benefit in this case needs to result from increased safety and product quality. ${ }^{9}$

Determination of these characteristics was done theoretically by Nagy et al. ${ }^{10}$, who proposed simple relationships of dimensionless numbers to determine whether dispersion or micromixing are important factors for performing a reaction in a given basic tubular or rectangular reactor channel. The effect of dispersion is studied through the Bodenstein number, Bo, calculated by:

$$
B o=\frac{u L}{D_{a x}}
$$

Whereby $\mathrm{u}$ is the linear flow rate, $\mathrm{L}$ is the channel length and $\mathrm{D}_{\mathrm{ax}}$ is the axial dispersion coefficient. Dispersion is considered low when Bo > 100, and ideal plug flow is obtained for Bo > 1000. ${ }^{10}$ Micromixing is studied through the Damköhler number, Da, which expresses the ratio of the rate of reaction to the rate of diffusion. If $\mathrm{Da}$ is larger than 1 (rate of reaction > rate of diffusion) the reactor delivers insufficient mixing. Nagy et al. ${ }^{10}$ present charts that show the Da and Bo for circular and square reactor channels under certain conditions. They also used a glycosylation reaction as a case study to show that the calculation of these two dimensionless numbers gives a good prediction of micromixing and dispersion effects on reactor performance. ${ }^{10}$ This method may be good for predicting the importance of mixing or dispersion. To affirm these predictions and get a true insight into mixing and flow behavior in a reactor setup, experimental characterization is needed. This is especially true for reactor performance comparison. Equations derived for simple geometries are not 
directly applicable for complex reactors. Experimental characterization however, can settle the question posed by Nagy et al. "does a simple $\mathrm{T}$ provide sufficient mixing or is a special micromixer warranted". 10

The characterization of dispersion and micromixing is performed using two commonly used techniques, the residence time distribution (RTD) and the Villermaux-Dushman reaction, respectively. RTD is more generally known for characterization of macromixing, or bulk mixing, and is used to study deviations from ideal plug flow. ${ }^{7,11}$ Measurement of the RTD is done through a stimulus-response experiment by monitoring the change in concentration of a non-reactive tracer as it passes though the reactor. ${ }^{7,11}$ Bošković et al. ${ }^{12}$ used RTD measurement to compare the performance of microfluidic mixers. Lueth et al. ${ }^{13}$ used RTD measurement to assess the effect of static mixers in a tubular reactor for continuous emulsion polymerization. Schwolow et al. ${ }^{14}$ used experimental RTD measurements combined with kinetic studies to accurately predict scale-up effects for a exothermic Michael addition. Micromixing efficiency can be determined through several different chemical reaction systems, of which an overview can be found in the paper of Aubin et al. ${ }^{15}$. One of the reaction-based characterization methods is the Villermaux-Dushman method, which is the most commonly used method for reactor performance comparison. ${ }^{2,14,16-21}$ The protocol was originally developed by Fournier et $a l^{22}$, for the characterization of industrial batch reactors. Several adaptations for the investigation of continuous micromixing reactors have since been presented. ${ }^{16,17}$ The method is based on two parallel competing reactions that result in the formation of an analytically detectable compound. The amount produced is a measure for the mixing quality. Comparison of the mixing performance of flow reactors is based on the measured absorbance (UV-VIS spectrophotometry) ${ }^{17-19,23}$ of this compound or calculated the segregation index, $\left(X_{s}\right)^{20}$ as a comparative parameter. This index is calculated from the absorbance of the mixing sensitive compound, together with the starting concentrations of the reagents. This makes the segregation indices strongly dependent on the reaction conditions used in the Villermaux-Dushman characterization. Several authors ${ }^{16,21,24,25}$ have discussed the need to adjust the concentration sets to characterize individual reactors. Panic et $a l{ }^{17}$, concluded that when comparing micromixing devices the acid and buffer concentration should stay the same for direct reactor comparison, but that acid concentrations can be varied to increase sensitivity. Because of the differences in concentrations sets used by different authors, direct comparison between these reactors based on the segregation index is impossible. ${ }^{26}$ This problem is overcome by converting the segregation index to the concentration-independent micromixing time, using a mixing model. In this study, the incorporation model, developed by Fournier et $a l^{27}$, is used as it is a flexible model for turbulent ${ }^{28}$ and laminar flow ${ }^{29}$.

The aim of this article is to characterize simple tubular reactors and complex commercially available reactor designs for performance comparison and indicate for which cases (reaction type A or B) a tubular reactor can serve as a cheaper alternative. This is done on two levels of mixing. Macromixing is studied through RTD measurements and micromixing through the Villermaux-Dushman protocol. Reactor selection based on reactor characterization and reaction type is discussed. To the authors knowledge this is the first publication that presents the characterization of the Chemtrix and LTF reactors based on RTD and the Villermaux-Dushman protocol.

\section{EXPERIMENTAL PROCEDURES}

\section{Continuous reactors}

The commercial glass chip reactors and coiled tube reactors used during characterization are shown in Table 1, together with the reaction volumes. Chip reactors are obtained from Chemtrix BV (KiloFlow ${ }^{\circledR}$ and Labtrix ${ }^{\circledR}$ ) (Geleen, The Netherlands) and Little Things Factory (Ilmenau, Germany) (LTF XXL-S-02, LTF XXL-ST-01, LTF micro-emulsifier). Coiled tube reactors consisted of PVC, ETFE or PMMA tubing with internal diameters of $0.4,0.7,1.6,2.4$, and $4.8 \mathrm{~mm}$ and were purchased from Reichelt Chemietechnik $\mathrm{GmbH}+$ Co. (Heidelberg, Germany). The 0.4 and $0.7 \mathrm{~mm}$ diameter tubes were fitted with a T-mixer, while the other tubular reactors were fitted with a Y-mixer for corresponding tube diameters (Reichelt Chemietechnik GmbH + Co., Heidelberg, Germany). The reactors with an inside diameter of 0.7, 1.6 and $2.4 \mathrm{~mm}$, have a coil diameter of $12 \mathrm{~cm}$ and the $0.4 \mathrm{~mm}$ ID tube reactor has a coil diameter of $7 \mathrm{~cm}$ or $60 \mathrm{~cm}$. The $1.6 \mathrm{~mm}$ ID tube reactor was also tested in a straight setup.

The largest tubular reactor (diameter $4.8 \mathrm{~mm}$ ) is also tested with a Kenics ${ }^{\circledR}$ helical design static mixer (Cole-Parmer, Metrohm Belgium n.v., Antwerp, Belgium) which has a split and recombine effect on the fluid. The internal volume of these tube reactors is experimentally determined by the gravimetric water content at $22{ }^{\circ} \mathrm{C}$ (density of water $=0.9978$ $\mathrm{g} / \mathrm{ml})$. 
Table 1: Overview of characterized reactor setups and internal volumes.

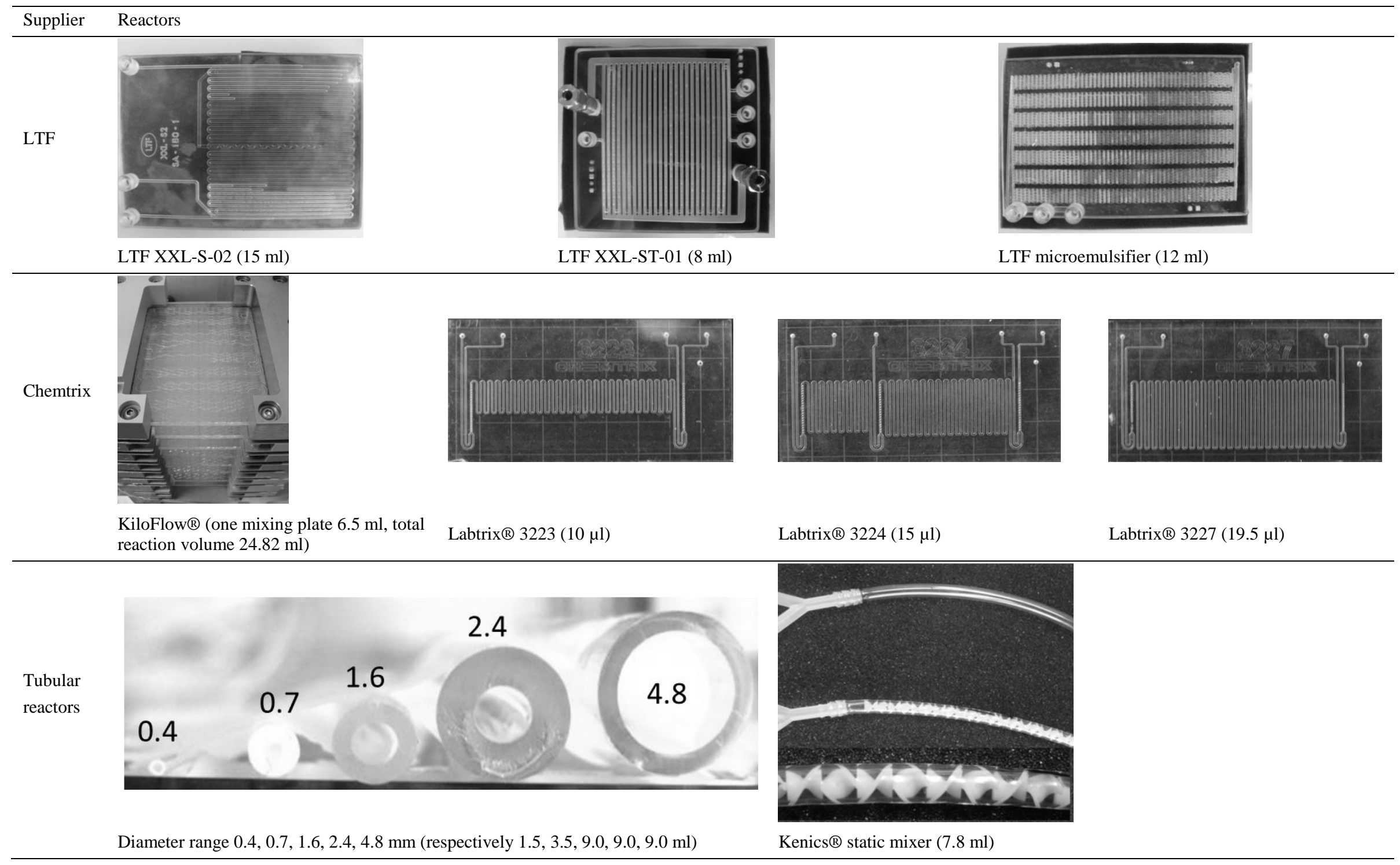




\section{Residence time distribution (RTD)}

\section{Reagents for RTD measurement}

The non-reactive tracer, $\mathrm{KCl}$ (Merk, Darmstadt, Germany) is used at a concentration of $0.01 \mathrm{M}$ to avoid changes to the physical properties of the fluid. A stock solution of $0.1 \mathrm{M} \mathrm{KCl}$ in ultrapure water is diluted with ultrapure water to $0.01 \mathrm{M}$ before each experiment.

\section{Determination of RTD}

A negative step experiment is implemented to determine the RTD curves of the tubular reactors, the LTF reactor and the Chemtrix KiloFlow ${ }^{\circledR}$. The Labtrix ${ }^{\circledR}$ reactors were not characterized with RTD measurements. The negative step input is generated by switching the $0.01 \mathrm{M} \mathrm{KCl}$ tracer feed to ultrapure water with the aid of a HPLC 6-way valve. The conductivity of the exit stream is monitored over time using a Model 3082-S-CE digital conductivity meter equipped with micro flow cell 829-CE (Amber Science Inc., Oregon, US). The channel of the flow cell has an internal diameter of $1 \mathrm{~mm}$ and has a volume of $166 \mu \mathrm{l}$. Measurements are registered every $400 \mathrm{~ms}$. The applied concentration step $(0.01 \mathrm{M}$ to $0 \mathrm{M}$ $\mathrm{KCl}$ ) corresponds to a step in conductance from $\sim 120 \mu \mathrm{S}$ to $0.055 \mu \mathrm{S}$, where the measured conductivity is proportional to the concentration of the tracer. One minus the relative conductance (ratio of conductance to maximum conductance) value is plotted versus time, to correct for the negative step, yielding the cumulative age distribution curve, $\mathrm{F}(\mathrm{t})$. The RTD curve, $E(t)$, is then obtained by numerical differentiation of the $\mathrm{F}(\mathrm{t})$ curve:

$E(t)=\frac{d F(t)}{d t}$

The normalized E-curve called $\mathrm{E}_{\ominus}$ is determined as follows:

$E_{\theta}=E(t) \cdot t_{\text {res }}$

Where $t_{\text {res }}$ is the mean residence time calculated as

$t_{\text {res }}=\int_{0}^{\infty} t E(t) d t \cong \sum_{t=0}^{\infty} t E(t) \Delta t$

In addition to the mean residence time, two more parameters quantifying the degree of mixing are calculated: the variance, $\sigma$ equation (4), which is a measure of the spread, and the covariance, $\mathrm{CoV}$, equation (5), representing the relative standard deviation.

$\sigma^{2}=\int_{0}^{\infty}\left(t-t_{r e s}\right)^{2} E(t) d t \cong \sum_{t=0}^{\infty}\left(t-t_{r e s}\right)^{2} E(t) \Delta t$

$\operatorname{CoV}=\frac{\sigma}{t_{\text {res }}}$

These two moments will indicate deviation from ideal plug flow. The RTD of plug flow is characterized by a symmetric residence time distribution with a spread $(\mathrm{CoV})$ of 0 . A spread or $\mathrm{CoV}$ larger than 0 indicates the presence of axial dispersion. $^{30}$

\section{Modelling of RTD data}

Experimental data are modelled using the two classical flow models, the axial dispersed flow and the pure convective flow model. Ideal plug flow is characterized by perfect mixing in the radial direction and no mixing in the axial direction, which is the direction of flow. The dispersion model is based on the dispersion number $\mathrm{D}_{\mathrm{ax}} / \mathrm{uL}$, which is a measure for back mixing. ${ }^{7}$ The normalized E-curve, $\mathrm{E}_{\theta}$, of the dispersion model has the following equation for small extents of dispersion $\left(\mathrm{D}_{\mathrm{ax}} / \mathrm{uL}<0.01\right)$ :

$E_{\theta}=\frac{1}{\sqrt{4 \pi\left(D_{a x / u L}\right)}} \exp \left(-\frac{(1-\theta)^{2}}{4\left(D_{a x / u L}\right)}\right)$

with $\theta=t / t_{r e s}$, and $t_{m}$ is the mean residence time. $D_{a x} / u L$ is the dispersion number with $\mathrm{D}_{\mathrm{ax}}$ the dispersion coefficient, $\mathrm{u}$ the linear velocity and $\mathrm{L}$ the length of the reactor. When the flow inside the reactor is dominated by a laminar flow resulting in a parabolic flow profile, the convection model is used. $^{7}$

$E_{\theta}=\frac{1}{1-\theta_{0}} \frac{1}{\theta}\left(\frac{\theta_{0}}{\theta}\right)^{1-\theta_{0}}$

Within the condition $\theta>\theta_{0}$. Whereby $\theta_{0}$ represents the break through time or minimal residence time.

The optimal fit between the models and the experimental data is determined with the least mean square method.

\section{Villermaux-Dushman method}

The Villermaux-Dushman method uses competing parallel reactions, shown in equations (a) (b) and (c). ${ }^{22}$

$\mathrm{H}_{2} \mathrm{BO}_{3}{ }^{-}+\mathrm{H}^{+} \rightleftarrows \mathrm{H}_{3} \mathrm{BO}_{3}$ (instantaneously)

$\mathrm{IO}_{3}{ }^{-}+5 \mathrm{I}^{-}+6 \mathrm{H}^{+} \rightleftarrows 3 \mathrm{I}_{2}+3 \mathrm{H}_{2} \mathrm{O}$ (fast)

$\mathrm{I}^{-}+\mathrm{I}_{2} \rightleftarrows \mathrm{I}_{3}^{-}$

Reaction (a) is a neutralization reaction of orthoboric acid and reaction (b) is the redox reaction of iodate and iodate ions to form elemental iodine. The acid is consumed in reaction (b) to form iodine which is in competition with the neutralization reaction. The iodine is converted to triiodide, which is detected through UV-Vis spectrophotometry and provides an indication of the micromixing quality. If mixing is ideal reaction (a) will consume all protons introduced into the reactor as it is much faster than reaction (b). If mixing is poor, local over-concentrations of protons will occur, enabling reaction (b) to take place. The measured amount of triiodide is converted to the segregation index which is a measure for the mixing quality.

\section{Reagents for Villermaux Dushman method}


The choice of concentration set is important to ensure triiodide formation is solely the result of poor mixing. All reactors are therefore characterized with the same concentration set shown in Table 2. Reagents were prepared fresh in demineralized water and protected from direct sunlight to avoid deterioration. The $\mathrm{pH}$ of solution 1 and 2 is measured with a $\mathrm{pH}$ meter (827 pH lab, Metrohm Belgium n.v., Antwerp, Belgium) and has a value of $10.7 \pm 0.1$ and $1.7 \pm 0.1$, respectively. The choice of the concentration set for solution 1 and 2 is justified by $\mathrm{pH}$ measurements of samples collected at the reactor exit. The exit $\mathrm{pH}$ stays in the basic range $8.8 \pm 0.1$ during the measurements for all experiments with different reactors at different flow rates. This confirms that the amount of triiodide is only due to poor mixing and no secondary reactions occur, as explained by Guichardon et al. ${ }^{16}$. The sulphuric acid solution is prepared with concentrated sulphuric acid (36N, Merck, Darmstadt, Germany). The second solution is prepared by first dissolving ortho boric acid (Merck, Darmstadt, Germany) and sodium hydroxide (VWR, Radnor, Pennsylvania, US) to make the buffer solution. Then the KI (VWR, Radnor, Pennsylvania, US) and $\mathrm{KIO}_{3}$ (ucb, Leuven, Belgium), are added to obtain final concentrations as indicated in Table 2.

Table 2: Composition of reagent solutions for the Villermaux-Dushman reaction.

\begin{tabular}{|l|l|l|}
\hline & Reagent & $\begin{array}{l}\text { Concentration } \\
(\text { mol. }\end{array}{ }^{-1}$ ) \\
\hline Solution 1 & $\mathrm{H}_{2} \mathrm{SO}_{4}$ & 0.015 \\
\hline Solution 2 & $\mathrm{H}_{3} \mathrm{BO}_{3}$ & 0.045 \\
\cline { 2 - 3 } & $\mathrm{NaOH}$ & 0.045 \\
\cline { 2 - 3 } & $\mathrm{KI}$ & 0.003 \\
\cline { 2 - 3 } & $\mathrm{KIO}_{3}$ & 0.016 \\
\hline
\end{tabular}

\section{Determination of mixing efficiency}

Continuous syringe pumps (Chemtrix BV, Geleen, The Netherlands) supplied the reagents to the reactor setup at equal flow rates. The total flow rate is adjusted to obtain residence times of 15, 30 and $60 \mathrm{~s}$ for each reactor setup. Continuous measurements are made with a Genysis $10 \mathrm{~S}$ spectrophotometer (Thermo Scientific, Waltham, Massachusetts, US) and by connecting the reactor exit to a quarts flow cell (Hellma Analytics, Müllheim, Germany) with an internal volume of $80 \mu \mathrm{l}$. Blanks with demineralized water are measured before each set of experiments. The Labtrix ${ }^{\circledR}$ microreactors with maximum flow rates of $80 \mu \mathrm{l} \mathrm{min}{ }^{-1}$ are characterized discontinuously. $100 \mu \mathrm{l}$ samples are collected and diluted to $600 \mu \mathrm{l}$ in ultrapure water and measured within 1 minute after taking a sample. Two wavelengths (353 and 410 $\mathrm{nm})$ are used to measure the triiodide formed in the exit stream. At $353 \mathrm{~nm}$, triiodide shows an absorbance maximum. A wavelength of $410 \mathrm{~nm}$ corresponds to a lower optical density (OD), enabling measurement when the triiodide concentration at $353 \mathrm{~nm}$ results in absorbance values above the linear range. The absorbance is registered every 5 seconds until steady state is obtained. Calibration curves were measured discontinuously at 353 and $410 \mathrm{~nm}$. Stock solutions were prepared by dissolving resublimated iodine (ucb,
Leuven, Belgium) in an excess of KI in ultrapure water. The extinction coefficient at $353 \mathrm{~nm}$ has an average value of $24,136 \pm 6521 . \mathrm{mol}^{-1} \cdot \mathrm{cm}^{-1}$, which corresponds well to the values recorded in literature (Table 3). The extinction coefficient at $410 \mathrm{~nm}$, has an average of $4066 \pm 138$ l.mol ${ }^{1} . \mathrm{cm}^{-1}$.

Table 3: Comparison of extinction coefficients of triiodide standard curve.

\begin{tabular}{|c|c|}
\hline Author & $\begin{array}{l}\text { Triiodide extinction } \\
\text { coefficient at } 353 \mathrm{~nm} \\
\left(1 . \mathrm{mol}^{-1} \cdot \mathrm{cm}^{-1}\right)\end{array}$ \\
\hline Fournier et $_{\text {al. }}{ }^{22}$ & 25,900 \\
\hline Guichardon et al. ${ }^{16}$ & 23,959 \\
\hline Falk et $a l .{ }^{25}$ & 26,047 \\
\hline Pinot et al. ${ }^{31}$ & 24,500 \\
\hline This work (average value $\mathrm{n}=21$ ) & 24,136 \\
\hline
\end{tabular}

The absorbance measurements are converted to the segregation index in order to compare results. The segregation index, as defined by Fournier et al. (1996), is the ratio of the experimental yield of reaction (b) to the yield of this reaction under total segregation conditions. ${ }^{22}$ In the latter case the reactions (a) and (b) take place according to their stoichiometry. Monnier et al. (2000) adapted the equations from Fournier for use in continuous reactors and assumed that the third reaction is complete under the experimental conditions. ${ }^{32}$ The same equations are used in this study and the amount of iodine formed is considered equal to the amount of triiodide measured. The segregation index is calculated as follows:

$\mathrm{X}_{\mathrm{s}}=\frac{\mathrm{Y}}{\mathrm{Y}_{\mathrm{ST}}}$

With ,

$\mathrm{Y}=2 \frac{\mathrm{F}_{\mathrm{I}_{3}^{-}}}{\mathrm{F}_{\mathrm{H}_{0}^{+}}}$

And

$\mathrm{Y}_{\mathrm{ST}}=\frac{6\left(\mathrm{IO}_{3}^{-}\right)_{0} /\left(\mathrm{H}_{2} \mathrm{BO}_{3}^{-}\right)_{0}}{6\left(\left(\mathrm{IO}_{3}^{-}\right)_{0} /\left(\mathrm{H}_{2} \mathrm{BO}_{3}^{-}\right)_{0}\right)+1}$

$F_{i}$ is the molar flux of species $i\left(\right.$ mol.s $\left.\mathrm{s}^{-1}\right)$ and is the product of the volumetric flow rate and the concentration of a reactant. The concentration of triiodide is quantified using the Law of Lambert Beer.

$\mathrm{Y}=2 \frac{Q_{\mathrm{I}_{3}}-\mathrm{C}_{\mathrm{I}_{3}^{-}}}{\mathrm{Q}_{\mathrm{H}_{0}^{+}} \mathrm{C}_{\mathrm{H}_{0}^{+}}}$with $\mathrm{C}_{\mathrm{I}_{3}^{-}}=\frac{\text { oD (at } 353 \text { or } 410 \mathrm{~nm})}{\varepsilon \mathrm{l}}$

The segregation index returns a maximum of 1 for a state of total segregation, while $\mathrm{Xs}=0$ indicates perfect mixing. 


\section{Determination of micromixing time}

The incorporation model describes the phenomena of mixing of the two reagent streams (acid and buffered iodide/iodate) as the introduction of an aggregate (liquid globule) containing only acid, which is the limiting reagent, in the surrounding buffered solution. The time it takes for the aggregate to be fully incorporated into the surrounding medium is equal to the micromixing time. The aggregate volume grows in function of time as the surrounding liquid is incorporated into the aggregate. The expansion of the aggregate volume, $\mathrm{V}_{\mathrm{a}}$, is described by the function $\mathrm{V}_{\mathrm{a}}=\mathrm{V}_{\mathrm{a} 0} \mathrm{~g}(\mathrm{t})$, with the incorporation function $g(t)=\exp \left(t / t_{m}\right)$. Whereby $t_{m}$ is the incorporation time which is considered equal to the micromixing time. The mass balance of the acid aggregate can be written for each species $\mathrm{i}$, including $\mathrm{H}_{2} \mathrm{BO}_{3}{ }^{-}, \mathrm{I}^{-}, \mathrm{IO}_{3}{ }^{-}, \mathrm{I}_{2}, \mathrm{I}_{3}{ }^{-}$and $\mathrm{H}^{+}$of the reaction (1), (2), (3), index $\mathrm{j}$ refers to the reactions that generate or deplete species $i$, see equations (a)-(c):

$\frac{\mathrm{dC}_{\mathrm{i}}}{\mathrm{dt}}=\left(\mathrm{C}_{\mathrm{i} 0}-\mathrm{C}_{\mathrm{i}}\right) \frac{1}{\mathrm{~g}} \frac{\mathrm{dg}}{\mathrm{dt}}+\mathrm{R}_{\mathrm{ij}}$

Where index 0 denotes initial conditions of the surrounding liquid, and $\mathrm{R}$ the reaction rate of production of species $\mathrm{i}$ in reaction $\mathrm{j}$. Substitution of $\mathrm{g}$ in equation 12 gives:

$\frac{d C_{i}}{d t}=\frac{\left(C_{i 0}-C_{i}\right)}{t_{m}}+R_{i j}$
Writing equation 17 for each of the mentioned ions results in 6 differential equations. The further treatment for solving the system of equations is discussed in detail by Kuang et $a l^{33}$ and Yang et $a l .{ }^{34}$ which studied mixing efficiency in flow reactors. The equations are solved for a series of chosen $t_{m}$ values. The integration stops when the acid concentration of the aggregate approaches zero, resulting in the concentrations $\left(\mathrm{I}_{2}\right.$ and $\left.\mathrm{I}_{3}{ }^{-}\right)$ needed to calculate the corresponding $X_{s}$. The $X_{s}$ versus $\mathrm{t}_{\mathrm{m}}$ curve is then used to convert the experimentally determined $X_{s}$ to $t_{m}$ values. Figure 1 shows the correlation of segregation index and the micromixing time determined by the incorporation model. All the experimentally measured $X_{s}$ are converted to the concentration independent micromixing time, using the linear section of the curve within the range of the experimental conditions, marked in Figure 1 by the rectangle. A range of $X_{s}$ from 0.003 to 0.136 corresponds to micromixing times of $2.10^{-4}$ and $1.10^{-2}$ which represent the minimum and maximum segregation indices measured out of all experiments.

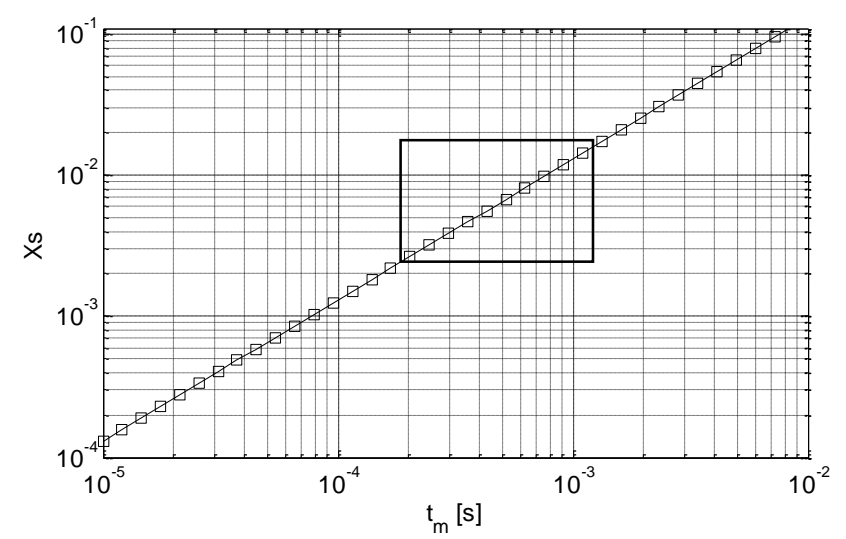

Figure 1: Segregation index, Xs, in function of micromixing time, $t_{m}$. the rectangle indicates the range of $X s$ and $t_{m}$ for experimental conditions indicated in Table 2.

\section{RESULTS AND DISCUSSION}

\section{RTD of tubular reactors}

Each reactor is characterized at 15,30 and 60 s residence time. The mean residence times calculated from the RTD measurements correspond well to the residence times calculated based on the experimentally determined reactor volume, see Table 4.

Table 4: Expected and measured mean residence times for tubular reactor with ID of $0.4,0.7,1.6,2.4,4.8 \mathrm{~mm}$.

\begin{tabular}{|l|l|l|l|}
\hline \multirow{2}{*}{$\begin{array}{l}\text { Tubular } \\
\text { reactor } \\
\text { diameter } \\
(\mathrm{mm})\end{array}$} & \multicolumn{4}{|l|}{ Expected mean residence time (s) } \\
\cline { 2 - 4 } & 15 & 30 & 60 \\
\cline { 2 - 4 } & \multicolumn{3}{|l|}{ Measured mean residence time (s) } \\
\hline 0.4 & $/$ & 35 & 62 \\
\hline 0.7 & 15 & 29 & 59 \\
\hline 1.6 & 14 & 27 & 56 \\
\hline 2.4 & 16 & 32 & 63 \\
\hline 4.8 & 14 & 27 & 56 \\
\hline
\end{tabular}


$\mathrm{E}_{\Theta}$-curves for tubular reactors, obtained at a residence time of $60 \mathrm{~s}$, are shown in Figure 2. The curve shape is a first indication of the type of flow in the reactor. For small tube diameters up to $1.6 \mathrm{~mm}$ a symmetric bell shaped curve is obtained, which indicates that the flow approaches plug flow and the dispersion model can be applied. As the diameter increases $(2.4-4.8 \mathrm{~mm})$ for the same residence time, the spread of the RTD curve increases. The strongest deformation is seen in the $4.8 \mathrm{~mm}$ ID tube reactor. Fluid element exit the reactor at half the residence time indicating a laminar flow profile.

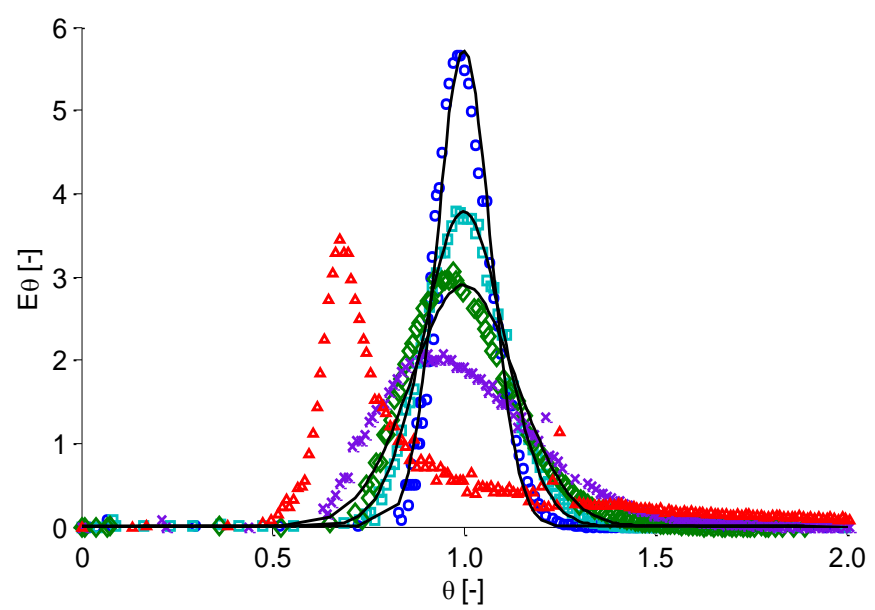

Figure 2: $\mathrm{E}_{\Theta}$ curve for tubular reactors with internal diameters of $0.4(\circ) ; 0.7(\square), 1.6(\diamond), 2.4(\times)$ and $4.8(\Delta) \mathrm{mm}$ at $60 \mathrm{~s}$ residence time. Dispersion model:-

For tubular reactors, the model to be used is derived from a diagram from Ananthakrishnan et $a .^{35}$, later adapted by Levenspiel et al. ${ }^{7}$. This diagram, for tubular reactors, is based on the intensity of dispersion, which is also called the Bodenstein number and the reactor geometry (reactor length to internal diameter ratio). To differentiate between the two Bodenstein numbers mentioned, the intensity of dispersion is symbolized by $\mathrm{Bo}^{*}$, and is defined as follows:

$$
\mathrm{Bo}^{*}=\frac{\mathrm{ud}_{\mathrm{t}}}{\mathrm{D}}
$$

where $d_{t}$ is the tube diameter and D is the diffusion coefficient. The positioning of the experimental conditions in the diagram is presented in Figure 3.

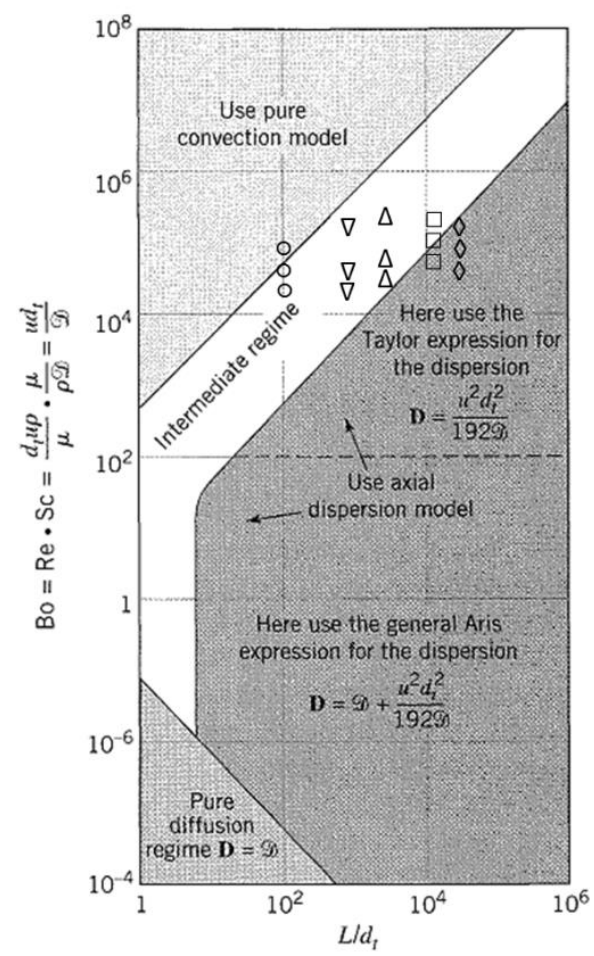

Figure 3: Placement of tubular reactors $0.4(\diamond), 0.7(\square), 1.6$ $(\Delta), 2.4(\mathrm{~V})$ and $4.8(\circ) \mathrm{mm}$, within diagram of Levenspiel et $a l^{7}$. (Adapted in part with permission from Levenspiel, O. Chemical reaction engineering. Chemical Engineering Science 19, (1999). Copyright 1999, John Wiley and Sons).

The 0.4 and $0.7 \mathrm{~mm}$ ID tube reactors should be modelled using the dispersion model. The 1.6 and $2.4 \mathrm{~mm}$ ID tube reactors are located in the intermediate zone for all experimental conditions, while the $4.8 \mathrm{~mm}$ ID tube reactor has one experimental condition (15 s residence time) in the zone of pure convection. The intermediate regime indicates the zone of the diagram where neither the dispersion flow nor pure convection flow model are ideal, but a hybrid model is needed. ${ }^{7}$ A good fit with the dispersion model is obtained for the experimental data of the $0.4,0.7$ and $1.6 \mathrm{~mm}$ ID tube reactors, see Figure 2. From the modelled $\mathrm{E}_{\theta}$ curves the dispersion numbers, $\mathrm{D}_{\mathrm{ax}} / \mathrm{uL}$, and Bo, are calculated, Table 5.

Table 5: Dispersion number for tubular reactors of $0.4,0.7$ and $1.6 \mathrm{~mm}$ internal diameter.

\begin{tabular}{|c|c|c|c|c|c|c|}
\hline \multirow{2}{*}{$\begin{array}{l}\text { Tube } \\
\text { diame } \\
\text { ter } \\
(\mathrm{mm})\end{array}$} & \multirow{2}{*}{$\begin{array}{l}\text { Coil } \\
\text { radius } \\
(\mathrm{cm})\end{array}$} & \multirow{2}{*}{$\begin{array}{l}\text { Reside } \\
\text { nce } \\
\text { time } \\
\text { (s) }\end{array}$} & \multicolumn{4}{|c|}{ Dimensionless parameter } \\
\hline & & & $\begin{array}{l}\mathrm{D}_{\mathrm{ax}} / \mathrm{uL} \\
\left(10^{-3}\right) \\
\text { (Experi } \\
\text { mental) }\end{array}$ & $\begin{array}{l}\text { Bo } \\
\text { (Exper } \\
\text { imenta } \\
\text { 1) }\end{array}$ & $\begin{array}{l}\text { Bo } \\
\text { (Taylor) }\end{array}$ & $\operatorname{Re}$ \\
\hline \multirow[t]{4}{*}{0.4} & \multirow[t]{2}{*}{7} & 30 & 3.0 & 338 & 36 & 160 \\
\hline & & 60 & 2.4 & 409 & 72 & 80 \\
\hline & \multirow[t]{2}{*}{60} & 30 & 4.5 & 224 & 36 & 160 \\
\hline & & 60 & 3.7 & 270 & 72 & 80 \\
\hline
\end{tabular}




\begin{tabular}{|l|l|l|l|l|l|l|}
\hline 0.7 & 12 & 15 & 17 & 59 & 6 & 420 \\
\cline { 3 - 7 } & & 30 & 11 & 88 & 12 & 210 \\
\cline { 3 - 7 } 1.6 & 60 & 5.6 & 179 & 24 & 105 \\
\cline { 3 - 7 } & 12 & 15 & 6.6 & 152 & 1 & 478 \\
\cline { 3 - 7 } & 30 & 7.8 & 128 & 2 & 239 \\
\cline { 3 - 7 } & 60 & 9.4 & 106 & 5 & 119 \\
\cline { 3 - 7 } & \multirow{3}{*}{$\begin{array}{l}\text { Straig } \\
\text { tube }\end{array}$} & 15 & $/$ & $/$ & 1 & 478 \\
\cline { 3 - 7 } & 30 & $/$ & $/$ & 2 & 239 \\
\cline { 3 - 7 } & 60 & $/$ & $/$ & 5 & 119 \\
\hline
\end{tabular}

\begin{tabular}{|l|l|l|l|l|}
\hline 0.7 & 12 & 33 & 16 & 8.0 \\
\hline 1.6 & 12 & 56 & 28 & 14 \\
\hline 2.4 & 12 & 46 & 23 & 11 \\
\hline
\end{tabular}

A Dn of 20, is considered a critical Dn, above which vortices are generated. ${ }^{38}$ This is the case for the high flow rate (i.e. 15 seconds residence time) in the 0.7, 1.6 and $2.4 \mathrm{~mm}$ ID tube reactors. However the $2.4 \mathrm{~mm}$ does not present ideal plug flow, which means that even though Dn $>20$, the radial mixing induced by the curvature of the tube is not strong enough to fully eliminate the parabolic velocity profile of the fluid stream. The $0.4 \mathrm{~mm}$ ID tube reactor has $\mathrm{Dn}<<20$, but still shows nearly ideal plug flow behavior (Table 5 ), for a coil diameter of 7 and $60 \mathrm{~cm}$. The increase in coil diameter resulted in an increase of the dispersion number, an indication that the spread of the RTD increased. This indicates that there is an effect of Dean vortices combined with the reduced diffusion distance that results in good radial mixing.

the flow in the reactor has only small deviations from ideal plug flow. Conversion of this threshold of axial dispersion number to Bo, gives $\mathrm{Bo}>100$. Table 5 also shows the theoretical Bo, calculated based on the Taylor correlation for the axial dispersion coefficient in straight tubes. ${ }^{36}$

$$
D_{a x}=\frac{u^{2} d_{t}^{2}}{192 D_{m}}
$$

According to the experimentally determined dispersion numbers, the small tubular reactors (0.4-1.6 mm ID) approach ideal plug flow (Bo near $(0.7 \mathrm{~mm}$ ) or larger than 100). Comparison of the experimental Bo values and the theoretic Bo values derived from the Taylor equation for the axial dispersion coefficient, shows an increase of a factor of 4 up to more than 100 in some cases. This indicates an improved state of radial mixing in the experimental setups. A contributing factor to this phenomenon is the fact that the tubular reactors are coiled, which is standard practice and induces flow in the radial direction due to centrifugal forces. This secondary flow perpendicular to the primary axial flow, contributes to a reduction in dispersion number and thus the spread of the RTD. ${ }^{14,37}$ This results in improved radial mixing through the coil shape, is given by the difference between the experimentally determined Bodenstein values that exceed a value of 100, compared to the Bo based on the Taylor correlation for straight tubes which are below 100. Characterization of the 1.6 $\mathrm{mm}$ ID tube reactor in a straight setup results in RTD curves representative of laminar flow for the three residence times. For this RTD curve no fit is possible with the dispersion model, and therefore no experimental dispersion number or Bodenstein number can be derived (Table 5). The Dean number is a measure for this secondary mixing phenomenon. Values for this dimensionless number are presented in Table 6, for the tubular reactors that are coiled during the characterization.

Table 6: Dean numbers for coiled tube reactors of $0.4,0.6$, 1.6 and $2.4 \mathrm{~mm}$ internal diameter.

\begin{tabular}{|l|l|l|l|l|}
\hline Tubular reactor & \multirow{2}{*}{$\begin{array}{l}\text { Coil } \\
\text { diameter }\end{array}$} & \multicolumn{2}{|l|}{ Dn } \\
\cline { 3 - 5 } $\begin{array}{l}\text { Internal diameter } \\
(\mathrm{mm})\end{array}$ & $\mathrm{cm})$ & $15 \mathrm{~s}$ & $30 \mathrm{~s}$ & $60 \mathrm{~s}$ \\
\hline 0.4 & 7.0 & $/$ & 12 & 6.0 \\
\cline { 3 - 5 } & 60 & $/$ & 4.0 & 2.0 \\
\hline
\end{tabular}

For larger tubular reactors $(2.4$ and $4.8 \mathrm{~mm}$ ) the dispersion model is no longer valid and the Bo cannot be calculated. The dispersion model nor the convection model result in an optimal fit. Especially at a shorter residence time (15 s) it becomes clear that the experimental data are a combination of the two models, see Figure 4. This corresponds with the expectations, based on Levenspiel's diagram. ${ }^{7}$ The $4.8 \mathrm{~mm}$ ID tubular reactor shows a larger deviation from ideal plug flow and a stronger resemblance to the pure convection model.

To focus on the effect of tube diameter and flow rate the $\mathrm{CoV}$ of the RTD curves is plotted as a function of the mean residence time, Figure 5. In larger diameters, the flow is no longer dispersed plug flow, but gains convection behavior which is indicated by an increase in $\mathrm{CoV}$. In the laminar flow the radial mixing is caused by diffusion between the layers of fluid with different flow rates. The diffusion time is calculated by, $t_{d}=d_{t}^{2} / 4 D$, where $d_{t}$ is the characteristic diffusion length, i.e. channel diameter, and $\mathrm{D}$ is the molecular diffusion coefficient. ${ }^{15}$ In the small tube reactors diffusion has a more significant contribution to radial mixing, due to the reduced diffusion distance. Figure 5Figure 5, also shows that the $\mathrm{CoV}$ decreases with longer residence times, i.e. slower flow rates. This means more time for diffusion, enabling radial mixing, which reduces the dispersion by averaging the flow rates of fluid elements over the tube cross-section. This makes small tube reactors, less influenced by the flow rate.

\section{RTD of tubular reactor with static mixer}

A Kenics ${ }^{\circledR}$ static mixer of $15 \mathrm{~cm}$ in length containing 24 mixing elements is placed in the beginning of the $4.8 \mathrm{~mm}$ ID tube reactor, directly after the Y-piece, and covers $30 \%$ of the reactor length. The RTD curves in Figure 6Fout! Verwijzingsbron niet gevonden. show the behavior of the flow at a residence time of $60 \mathrm{~s}$. Both curves show strong laminar flow. Similar shaped curves were obtained for residence times of 15 and $30 \mathrm{~s}$. The RTD of the tube with static mixer shows a slight shift of the curve peak towards 1 , and there is a small reduction in the spread at residence times 
of 30 and $60 \mathrm{~s}$. Using CFD modelling Lueth et al. ${ }^{13}$ have demonstrated that the static mixer creates a vortex. This vortex extended for $11.25 \mathrm{~cm}$ in a curved tube at flow rates of 66 ml.min ${ }^{-1}$ and the vortex length was not influenced by the number of static mixer elements. In the current experiments a maximum flow rate of $36 \mathrm{ml} . \mathrm{min}^{-1}$ is used in a straight tube setup, which results in a shorter vortex length after the mixing elements. Figure 7 shows how the RTD deforms as the measurements are performed further downstream of the static mixer $(0,1,5$ and $15 \mathrm{~cm}$ after the static mixer). At $0 \mathrm{~cm}$ after the static mixer the flow behavior still shows large deviations from plug flow, however the RTD curve has a more bell shaped curve and has a lower spread $(\mathrm{CoV}=23 \%)$, compared to the measurement at $15 \mathrm{~cm}(\mathrm{CoV}=59 \%)$. The RTD measured at $15 \mathrm{~cm}$ after the static mixer overlaps almost perfectly with the RTD curve measured at the reactor's full length. It is most likely that plug flow can be achieved when a higher flow rate is tested, that results in a well-defined vortex, and as long as the measurement is performed close to the static mixer exit. In the current experiment the vortex is weak and is extinguished within $1 \mathrm{~cm}$ after the static mixer, converting to laminar flow in the remainder of the reactor before the flow reaches the conductivity meter. Filling the reactor completely or partially with static mixers as suggested by Lueth et al. ${ }^{13}$, will lead to dispersed plug flow, i.e. an improvement of the RTD.
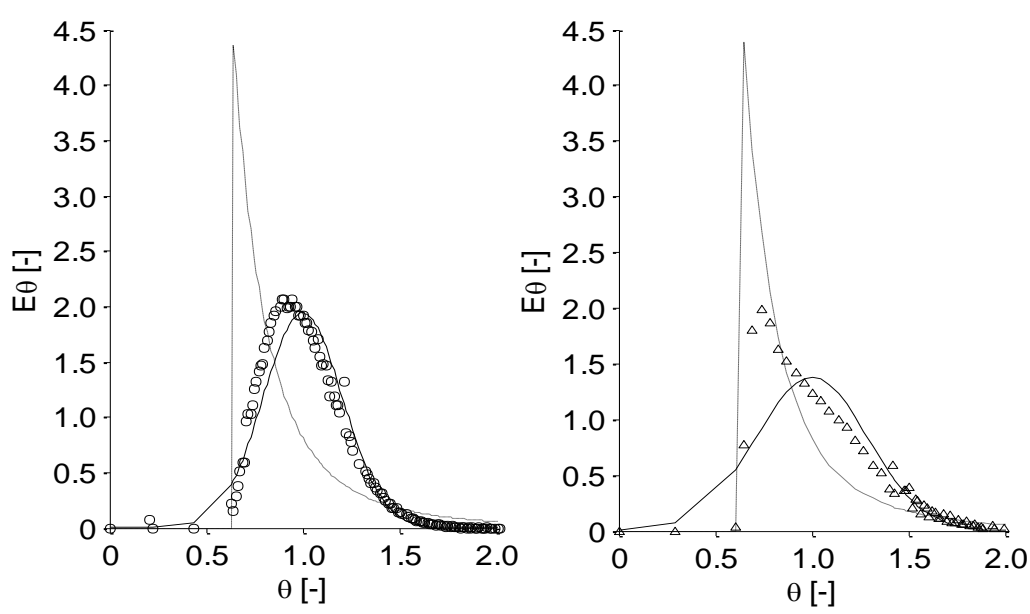

Figure 4: $\mathrm{E}_{\Theta}$ curve for a tubular reactor with an internal diameter of $2.4 \mathrm{~mm}$ at a residence time $56 \mathrm{~s}(\circ)$ and $14 \mathrm{~s}(\Delta)$. The experimental data points are shown together with the fitted dispersion and convection model. Dispersion model:- , convection model: - - -

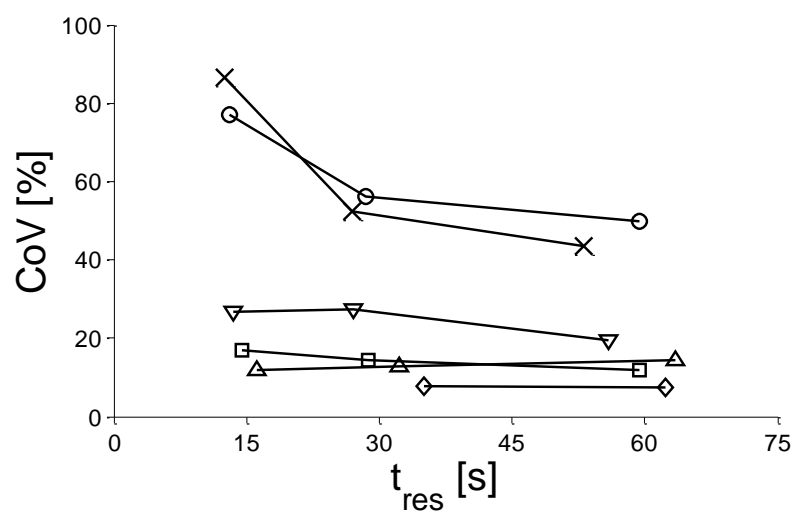

Figure 5: CoV for tubular reactors $0.4(\diamond), 0.7(\square), 1.6(\Delta), 2.4(\vee)$ and $4.8(\circ) \mathrm{mm}$, and $4.8 \mathrm{~mm}$ tube reactor with Kenics static mixer $(\times)$. Experimental data points are connected to indicate trends in the results. 


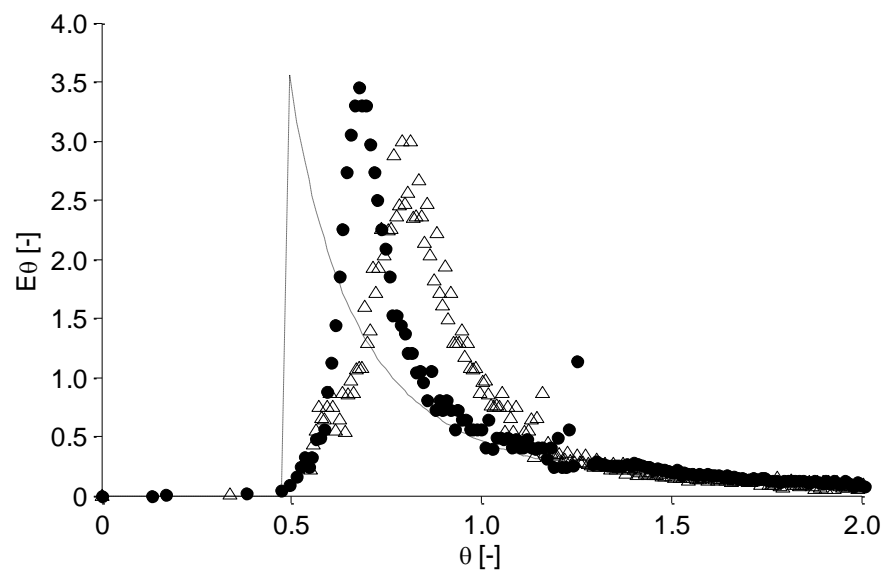

Figure 6: $\mathrm{E}_{\ominus}$ curve for the tubular reactor with a $4.8 \mathrm{~mm}$ diameter with a Kenics ${ }^{\circledR}$ static mixer $(\Delta)$ and without $(\bullet)$ at a residence time of 60 s. Convection model: - - -.

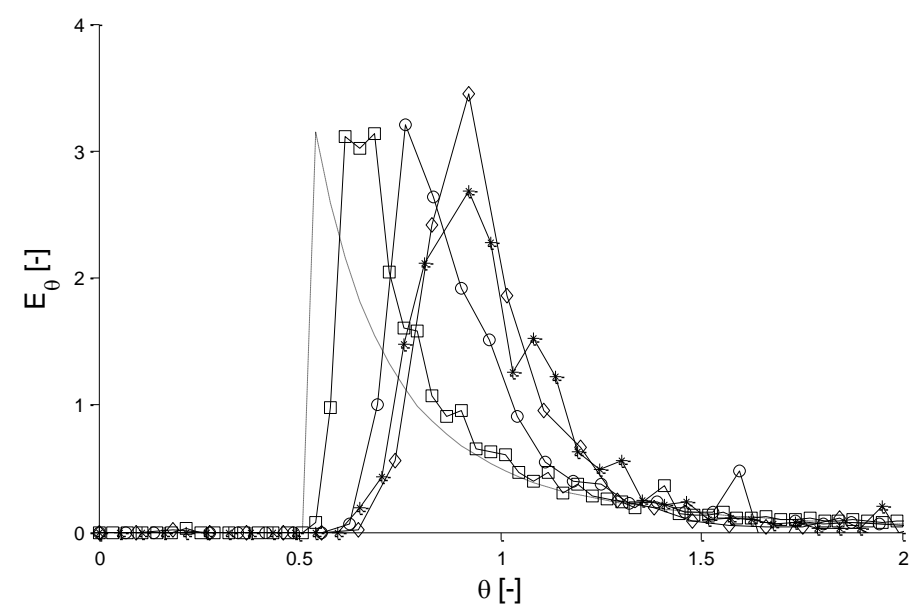

Figure 7: $\mathrm{E}_{\Theta}$ curve for $4.8 \mathrm{ID}$ tubular reactor with static mixer, measurements taken at $0 \mathrm{~cm}(*), 1 \mathrm{~cm}(\diamond), 5 \mathrm{~cm}(\circ)$ and $15 \mathrm{~cm}(\square)$ after the static mixer. Convection model: - - -.

\section{RTD of chip reactors}

Figure 8 shows the $\mathrm{E}_{\Theta}$ curves for all the chip reactors at $60 \mathrm{~s}$ residence time. The RTD curves of the LTF-XXL-S-02 and ST-01, reactors are narrower and more symmetric than the LTF micro emulsifier and the Chemtrix Kiloflow®. The RTD data of these first two reactors are fitted with the dispersion model.

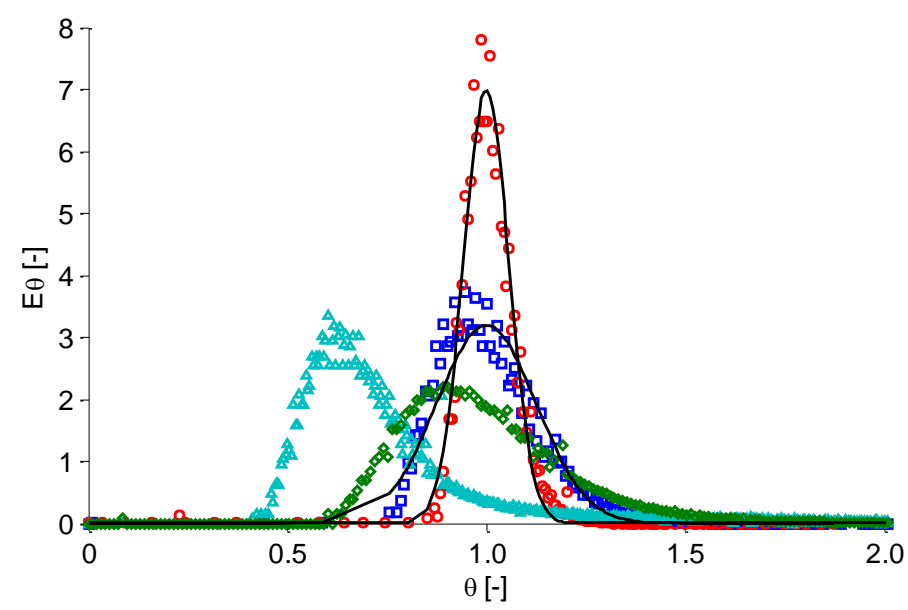

Figure 8: $\mathrm{E}_{\Theta}$ curve for chip reactors LTF-XXl-ST-01(०), LTFXXL-S-02 $(\square)$, Kiloflow ${ }^{\circledR}(\diamond)$, LTF micro emulsifier $(\triangle)$ mm LTF at a residence time of $60 \mathrm{~s}$. Dispersion model: - 
The dispersion numbers obtained are shown in Table 7 and have Bo > 100 for all tested residence times in the LTF XXLST-01 and LTF XXL-S-02. The LTF-XXL-ST-01 has lower dispersion numbers than the XXL-S-02. This indicates that the LTF XXL-ST-01 gives better radial mixing. The difference between the LTF-XXL-S-02 and LTF-XXL-ST-01 is mainly in static mixer geometry and the distribution of the static mixers over the channel length. The XXL-S-02, has a short mixing structure between a preheating channel and a residence time channel. The XXL-ST-01 has a more complex ST-type static mixer that covers the total channel length. This results in better radial mixing that is maintained over the total channel length. The LTF micro emulsifier and Chemtrix Kiloflow ${ }^{\circledR}$ show a large deviation from ideal plug flow. The flow entering these reactors is divided over a number of small channels, which in turn have split and recombine structures. This increases the number of possible flow paths that the fluid elements can follow resulting in a larger spread on the RTD.

Table 7: Dispersion numbers of the LTF XXL-ST-01 and XXL-S-02 reactor at 15,30 and 60 s residence time.

\begin{tabular}{|l|l|l|l|l|}
\hline \multirow{2}{*}{ Residence time } & \multicolumn{2}{|l|}{ LTF-XXL-S-02 } & \multicolumn{2}{l|}{ LTF-XXL-ST-01 } \\
\cline { 2 - 5 } & $\begin{array}{l}\mathrm{D}_{\mathrm{ax}} / \mathrm{uL} \\
\left(10^{-3}\right)\end{array}$ & Bo & $\begin{array}{l}\mathrm{D}_{\mathrm{ax}} / \mathrm{uL} \\
\left(10^{-3}\right)\end{array}$ & Bo \\
\hline 15 & - & - & 1.0 & 1001 \\
\hline 30 & 7.8 & 136 & 1.3 & 777 \\
\hline 60 & 7.3 & 128 & 1.6 & 613 \\
\hline
\end{tabular}

Figure 9 shows the $\mathrm{CoV}$ of the chip reactors. The reactors can be ranked from low dispersion to high dispersion as follows: LTF XXL-ST-01, LTF XXL-S-02, Kiloflow ${ }^{\circledR}$ and LTF emulsifier. The LTF XXL-ST-01 and XXL-0-2 have a similar $\mathrm{CoV}$ as the $0.4 \mathrm{~mm}$ ID tubular reactor, see Figure 5 and Figure 9. These LTF-reactors have a square reactor channel with a larger cross section than a $0.4 \mathrm{~mm}$ ID tube reactor $\left(4.8 \mathrm{~mm}^{2}\right.$ versus $0.13 \mathrm{~mm}^{2}$ for a $0.4 \mathrm{~mm}$ ID tube reactor) and a square reactor channel, making them more susceptible to dispersion as the corners of the square channel retain fluid. ${ }^{10}$ However thanks to the static mixer these reactor plates still have narrow RTD curves. A larger cross-section allows for a larger through-put, this means that scale-up from the tubular microflow reactor to the milliflow chip reactor is possible without compromising the RTD. The spread of the RTD of the Kiloflow ${ }^{\circledR}$ is equal to a $2.4 \mathrm{~mm}$ ID tube reactor, while the LTF micro emulsifier approaches $\mathrm{CoV}$ similar to a $4.8 \mathrm{~mm}$ ID tube reactor.

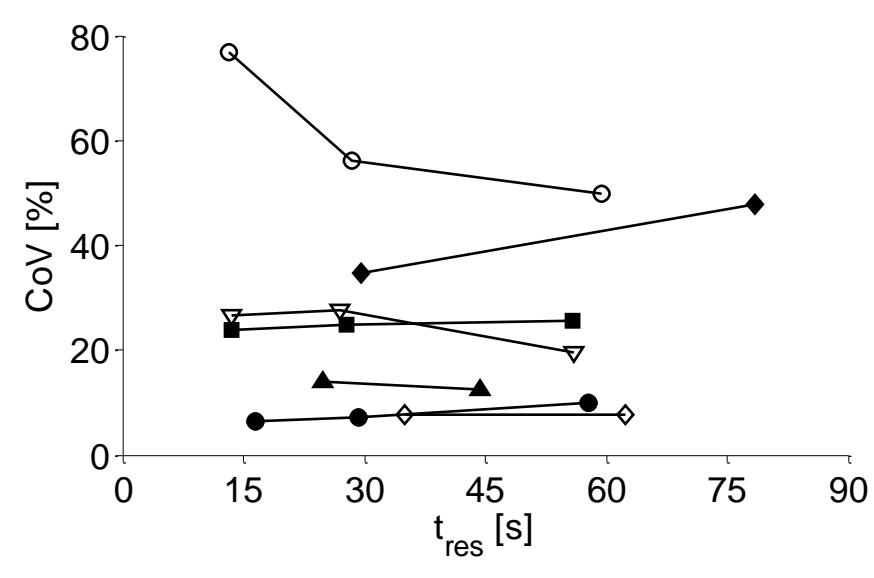

Figure 9: Covariance in function of the residence time for tube reactors with reactors $0.4(\diamond), 2.4(\mathrm{~V})$ and $4.8(\circ) \mathrm{mm}$ internal diameter and chip reactors from LTF-XXL-S-02 ( $\Delta)$, LTF-XXLST-01 (•), LTF micro emulsifier $(\bullet)$ and Chemtrix Kiloflow ${ }^{\circledR}$ (匹).

\section{Mixing performance of tubular reactors}

Results of the micromixing time are shown in Figure 10 a and b. The flow rate, which is inversely correlated to the mean residence time, $t_{r e s}(x$-axis of Figure 10), influences the micromixing quality in a positive way. By means of Figure 10 $\mathrm{b}$, it is clear that an increase in Reynolds numbers, due to an increase in linear flow rate, the micromixing time reduces. Mixing in these tubular reactors is induced by the interaction of the two reagent streams, in a $\mathrm{T}$ or $\mathrm{Y}$-junction at the reactor entrance. Depending on the flow rate and the geometry of the inlet and the mixing channels, vortices are generated that induce engulfment flow. Even though laminar flow is expected because of low Reynolds numbers, $40 \leq \operatorname{Re}<400$, Figure $10 \mathrm{~b}$, this engulfment of the two streams can still be present. ${ }^{39}$ Soleymani et $a l .{ }^{40}$ have shown this engulfment flow at low Reynolds numbers for T-type micromixers with square channels, with mixing channel height ranging from 0,8 to 1.6 $\mathrm{mm}$. As the flow rate increases so does the collision energy and thus the energy dissipation rate, resulting in more engulfment, leading to an increase in interfacial area. This benefits diffusion, which is still the rate determining step of micromixing, and consequently lowers the micromixing time. The micromixing also improves with decreasing diameter at equal Reynolds numbers, see Figure $10 \mathrm{~b}$, for the tubular reactor with internal diameters of 0.4 and $4.8 \mathrm{~mm}$, tested at Reynolds number equal to 40,80 and 160 . The decrease in reactor diameter, reduces the length scale of the molecular diffusion between lamellae and consequently reduces the diffusion and thus micromixing time.

Of the tubular reactors, the $0.4 \mathrm{~mm}$ ID tube reactor has the lowest micromixing time of $2.3 .10^{-3} \mathrm{~s}$, at a total residence time of 35 seconds. In the large tubular reactor of $4.8 \mathrm{~mm} \mathrm{ID}$, the micromixing time at $28 \mathrm{~s}$ residence time is four times higher. By introducing a Kenics ${ }^{\circledR}$ static mixer the micromixing time is reduced and approaches the micromixing time of the $0.4 \mathrm{~mm}$ ID tube reactor, Figure $10 \mathrm{a}$ and $\mathrm{b}$. Note that in Figure $10 \mathrm{~b}$, the Reynolds numbers of the $4.8 \mathrm{~mm}$ tubular reactor with and without static mixer are the same, 
based on equation $R e=\frac{\rho u d}{\mu}$. However with a static mixer there will be more turbulence, the actual Reynolds numbers are expected to be higher. The static mixer is able to increase the interfacial area between alternating fluid lamellae of different reagent concentrations, which reduces the diffusion distance and increases radial mixing. ${ }^{3}$

To study the effect of reactor length the $0.4 \mathrm{~mm}$ ID tube reactor is reduced from 12 to $1 \mathrm{~m}$ and characterized under the same flow conditions. Residence times of 30 and $60 \mathrm{~s}$ in the $12 \mathrm{~m}$ reactor correspond to residence times of 5.0 and $9.9 \mathrm{~s}$ in the $1 \mathrm{~m}$ tube reactor. There is no significant difference in the segregation indices obtained and the corresponding micromixing time is in the order of $10^{-3} \mathrm{~s}$. The remaining 11 meters have no major contribution to the mixing quality This result is similar to tests performed by Panic et al. ${ }^{17}$, who investigated the influence of additional residence time between a micromixer and the spectrophotometer. This means that, in the case of reactions that become kinetically controlled due to short micromixing times, the reactor volume can be greatly reduced according to the necessary reaction time. Threshold values for the micromixing time, to obtain kinetically controlled conditions for a certain reaction, are given through the mixing Damköhler in a later section. These results also highlight the fundamentals of the VillermauxDushman protocol. It is based on fast chemical reactions it is only suited for the characterization of initial mixing at the reactor entrance. Mixing effects further along in the reactor, which are very important for heterogeneous reactions, are not measurable with this method.

\section{Mixing performance of chip reactors}

Figure 11 shows that the Labtrix ${ }^{\circledR}$ reactors have very similar micromixing times regardless of the flow rate (or residence time). The Kiloflow ${ }^{\circledR}$ also has micromixing times below $10^{-3}$. Both reactors have the same SOR (staggered oriented ridge) mixing structure to mix the reactants in the beginning of the reactor chip. Chemtrix presented similar results, based on another characterization method, the fourth Bourne reaction. This makes scaling from the microflow to the milliflow setup possible without the need for re-optimization of process parameters. $^{41}$

The LTF XXL-S-02 and the LTF XXL-ST-01 chip reactors have similar micromixing times, see Figure 12, and have micromixing times comparable to the Chemtrix Kiloflow ${ }^{\circledR}$ at high flow rates. As previously mentioned the VillermauxDushman protocol characterizes initial mixing. In the XXL-S01 , the reagents interact in a T-piece and pass subsequently directly over the static mixer. In the XXL-ST-01 the two reagent streams enter the reactor next to each other in the same channel and continue directly into the static mixer.

\section{Reactor characterization as a basis for reactor selection}

Bourne assessed the mixing sensitivity of reactions through the mixing Damköhler number, $\mathrm{Da}_{\mathrm{M} \cdot}{ }^{11,42}$ This number is calculated as follows:

$D a_{M}=\frac{t_{m}}{t_{r}}$
Whereby $t_{m}$ is the micromixing time and $t_{r}$ the reaction time. Three regions of mixing sensitivity are defined:

$\mathrm{Da}_{\mathrm{M}}<0.001$ the reaction becomes kinetically controlled.

$\mathrm{Da}_{\mathrm{M}}>1000$ the reaction is limited by mixing, the reaction rate is much larger than the mixing rate.

$0.001<\mathrm{Da}_{\mathrm{M}}<1000 \quad$ both micromixing and reaction kinetics are important.

A $\mathrm{Da}_{\mathrm{M}}$ below 0.001 is then used to define maximum mixing time limits that are beneficial for type $\mathrm{A}$ and $\mathrm{B}$ reactions. Type A reactions are extremely fast reactions, with reaction times ranging from $10^{-9}$ (acid-base reaction) to 1 second. This corresponds to required mixing times of maximum $10^{-12}$ and $10^{-3} \mathrm{~s}$ respectively. Type $\mathrm{B}$ reactions range from $1 \mathrm{~s}$ to $10 \mathrm{~min}$ reaction time, and would require maximum mixing times between $10^{-3} \mathrm{~s}$ and $0.6 \mathrm{~s}$. For type A reactions in the upper range of reaction times, the chip reactors with small internal dimensions and static mixers (Chemtrix and LTF) are suitable. These reactors show micromixing times in the range of 0.2 $.10^{-3}-0.7 .10^{-3} \mathrm{~s}$ (Figure 12). The shortest micromixing times so far reported in literature are $10^{-5} \mathrm{~s}$ in a impinging streamrotating packed bed reactor ${ }^{43}$ and $0-10^{-4} \mathrm{~s}$ in packed microchannels ${ }^{44}$. The plate reactors are also suited for type B reactions, but small tubular reactors (ID $\leq 1.6 \mathrm{~mm}$ ) equipped with a simple $\mathrm{T}$ - or Y-piece, can serve as cheaper alternatives, reaching micromixing times less than $5.10^{-3} \mathrm{~s}$. The lack of mixing structures causes these tube reactors to be more sensitive to flow rate compared to chip reactors. A tubular reactor needs a certain minimal flow rate to achieve good mixing, i.e. short micromixing times. When building a tubular reactor, this minimal flow rate needs to be taken into account to determine the reactor length to obtain a desired residence time. By introducing a static mixer into a tube reactor, the micromixing time is reduced substantially (by a factor of four) in comparison to the empty tube, shown in this study with a Kenics ${ }^{\circledR}$ static mixer, making a $4.8 \mathrm{~mm}$ ID tubular reactor with static mixer suitable for a larger range of type $B$ reactions. This is very important for scale up. High flow rates in a small tubular reactor results in an unpractical reactor length, to maintain a certain residence time, and consequently result in a large pressure drop. By increasing the reactor diameter and using a static mixer, the throughput can be increased and mixing performance can be maintained in a shorter reactor. However it is important to also consider heat transfer properties, which are influenced by the wall thickness and the reactor diameter.

Fast reactions which yield a single product that is stable in time are less influenced by the residence time distribution, because the product is formed right at the beginning of the reactor. In case of fast consecutive reactions, described in general terms by:

$\{A+B \rightarrow R$

$\left\{\begin{array}{l}A+B \rightarrow S \\ \text {, }\end{array}\right.$

the mixing time of the reactor needs to be lower than the reaction time ( $95 \%$ conversion) of the first reaction, if $\mathrm{R}$ is the desired product. ${ }^{45}$ Furthermore, the residence time of $\mathrm{R}$ inside the reactor will determine the amount of by-product $S$ that is formed. The desired residence time corresponds to the moment when the concentration of product $\mathrm{R}$ is at a maximum, while the concentration of product $\mathrm{S}$ is still at an 
acceptable low level. The RTD of the reactor has to be as narrow as possible, to ensure each fluid element has the same residence time. The LTF-XXL-S-02 and -ST-01 and the small tubular reactors (ID $=0.4,0.7$ or $1.6 \mathrm{~mm}$ ) fulfil these requirements. They have short micromixing times and display nearly ideal plug flow behavior $\left(\mathrm{D}_{\mathrm{ax}} / \mathrm{uL}<10.10^{-3}\right)$. These reactors are suited for type $\mathrm{B}$ reactions, which are slower and kinetically controlled in fast mixing reactors. ${ }^{9}$ The reaction now takes place further along the reactor, past the initial mixing zone. As the residence time becomes a more important parameter so does the RTD. In this case making a choice between a chip reactor and a small tubular reactor, which also display a narrow RTD, comes down to other selection criteria, for instance heat transfer or solid-handling, depending on the reaction to be considered.
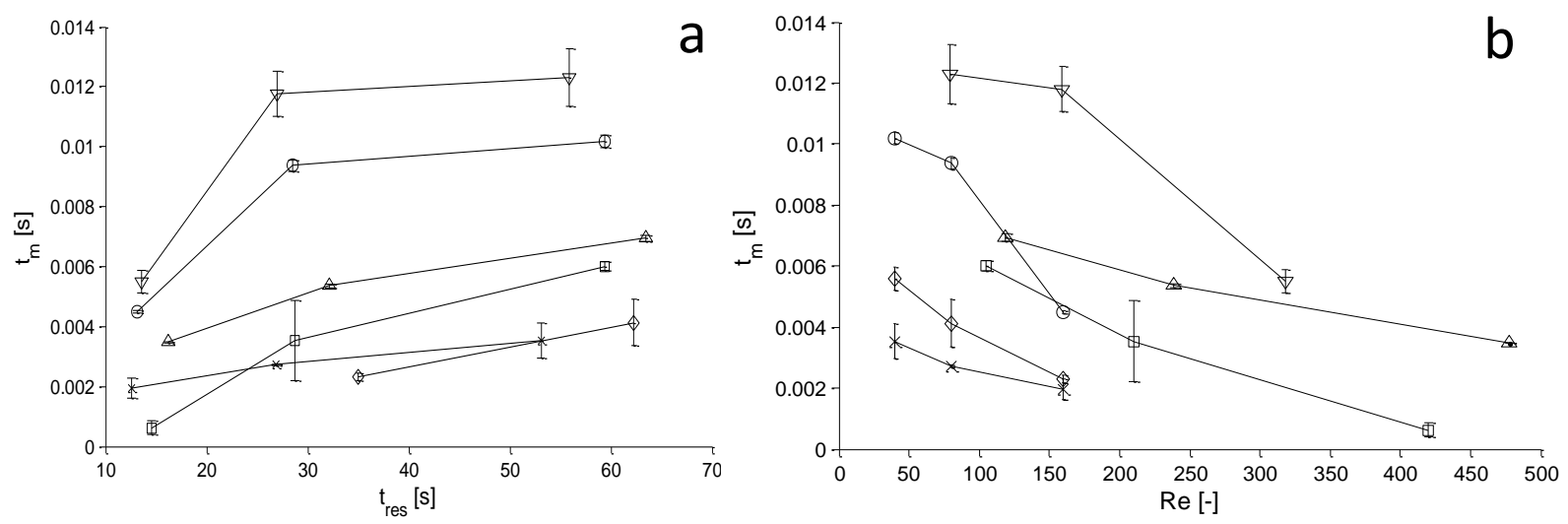

Figure 10: Micro mixing time of tube reactors with $0.4(\diamond), 0.7(\square), 1.6(\Delta), 2.4(\vee)$ and $4.8(\circ) \mathrm{mm}$, and 4.8 mm tube reactor with Kenics ${ }^{\circledR}$ static mixer $(x)(n=2)$.

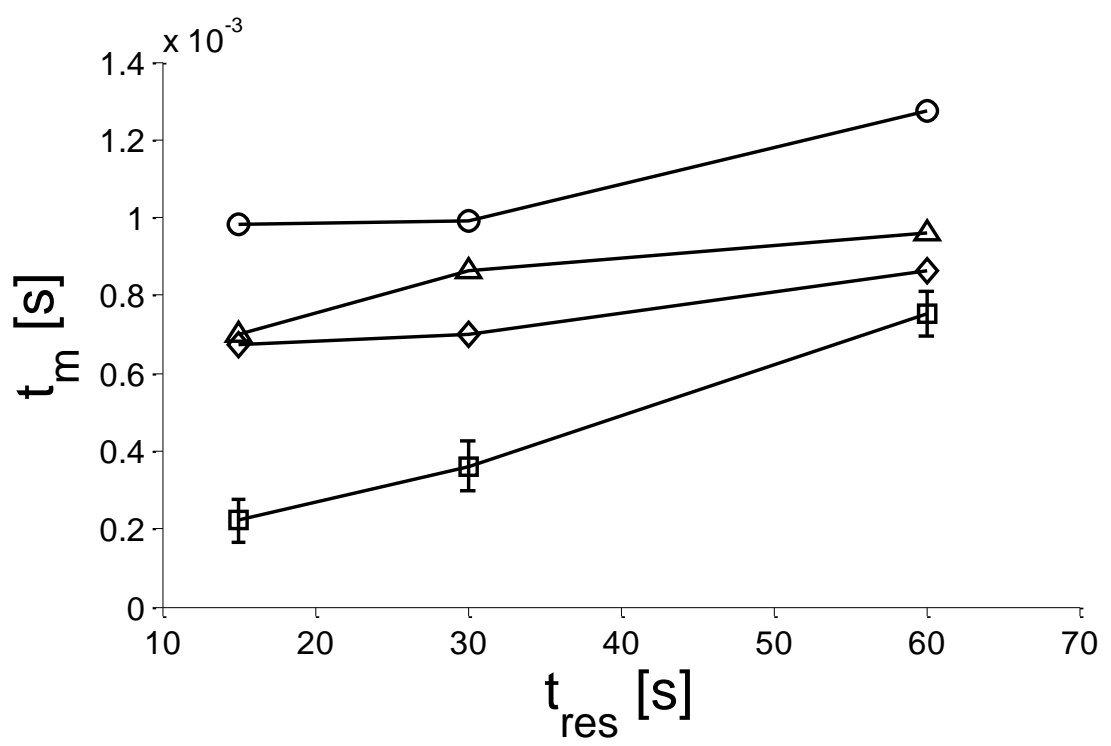

Figure 11: Micromxing time of Chemtrix reactors, Labtrix ${ }^{\circledR} 3223(\circ), 3224(\Delta), 3227(\diamond)(n=1)$ and Kiloflow® $(\square)(n=4)$. 


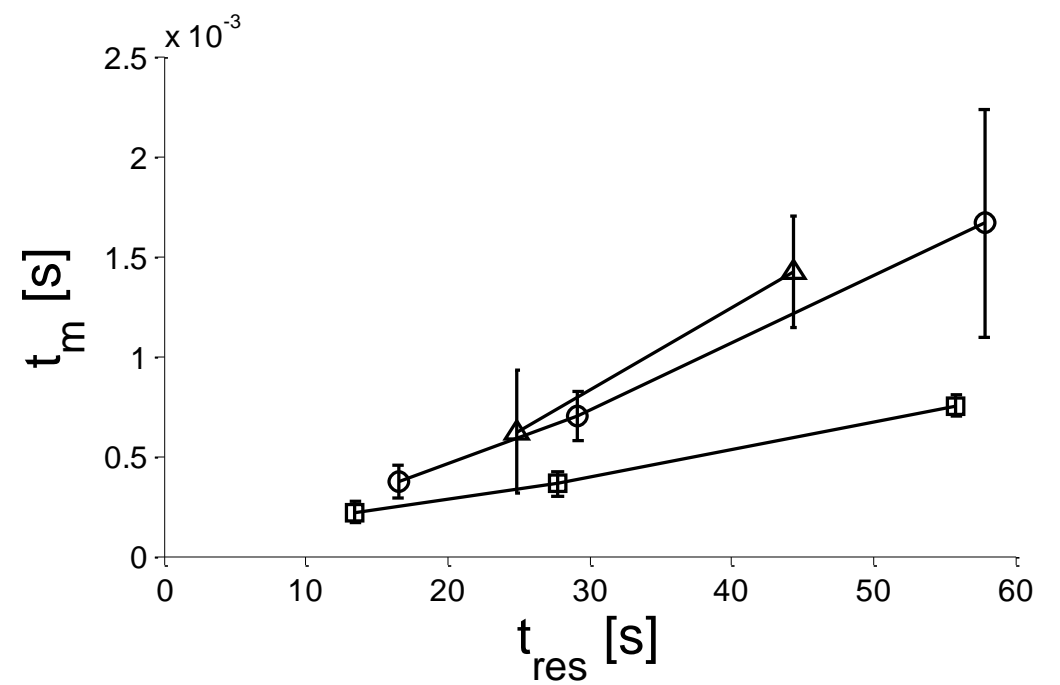

Figure 12: Micromixing time of LTF reactors XXL-S-02 $(\Delta)$ and XXL-ST-01 $(\circ)(\mathrm{n}=2)$ and Kiloflow $(\square)(\mathrm{n}=4)$. 


\section{CONCLUSION}

This paper presents new data on the characterization of commercial micro- and milli-flow reactors, including Chemtrix Kiloflow ${ }^{\circledR}$ and labtrix ${ }^{\circledR}$ setups and LTF chips XXLS-02 and -ST-01. These complex reactors are compared to a wide range of classical tubular reactors, ranging from 0.4 to $4.8 \mathrm{~mm}$ ID. Mixing performance is measured on two different levels. Macromixing is characterized through RTD, which is measured through a step-down experiment of tracer, and micromixing time is determined with the VillermauxDushman protocol and the incorporation model. These characterization techniques are easily performed, require basic reagents and are applicable to a large range of reactors. They also facilitate reactor selection, based on the requirements of the reaction type. Fast reactions, (half-life's $<1$ s), denoted by Roberge et al. ${ }^{9}$ as type A reactions, benefit from fast initial mixing. For these reactions, the chip reactors (Kiloflow ${ }^{\circledR}$, Labtrix ${ }^{\circledR}$, LTF-XXL-ST-01, -XXL-02) are preferable because of their short micromixing times in the order of $10^{-3} \mathrm{~s}$. In tubular reactors the mixing quality in these reactors is dependent on flow rate, internal diameter and the use of static mixers. Higher flow rates result in more turbulence and consequently shorter micromixing times. Tube reactors need a certain minimum flow rate to obtain good mixing. Small tubular reactors $(0.4-1.6 \mathrm{~mm})$ show better micromixing. By introducing a static mixer (shown for a $4.8 \mathrm{~mm}$ ID tube reactor equipped with Kenics ${ }^{\circledR}$ mixer) the micromixing is improved substantially. Type B reactions with reaction times up to 10 min are less sensitive to micromixing and are more influenced by the residence time distribution. Within the tested Reynolds number regime (40-400) small coiled tubular reactors of 0.4 , 0.7 and $1.6 \mathrm{~mm}$ ID, are modelled with the dispersion model, showing nearly ideal plug flow with dispersion numbers below $10.10^{-3}$ (Bo > 100). The dispersion increases as the diameter increases, whereby a tubular reactor with an ID of $4.8 \mathrm{~mm}$ presents almost pure laminar flow in a Reynolds number range of 40-160. Introduction of a Kenics ${ }^{\circledR}$ static mixer shows a reduction in the spread of the RTD, but only in the vicinity of the static mixer, where a vortex is generated. Chip reactors from LTF-XXL-S-02 and -ST-01, which have a single channel with static mixers also displayed nearly ideal plug flow behavior $\left(\mathrm{D}_{\mathrm{ax}} / \mathrm{uL}<10.10^{-3}\right)$. The LTF micro emulsifier and Chemtrix Kiloflow $®$, which divide the entering streams into a network of channels, display more dispersion, and are therefore less suited for the RTD sensitive type B reactions.

\section{AUTHOR INFORMATION}

\section{Corresponding Author}

* E-mail: sven.gobert@kuleuven.be;

leen.thomassen@kuleuven.be

\section{ACKNOWLEDGMENT}

We acknowledge the financial support from the Agency for Innovation by Science and Technology (IWT) No. 130190.

\section{ABBREVIATIONS}

$\mathrm{C}_{\mathrm{i}} \quad$ concentration of species $\mathrm{i}, \mathrm{mol} \mathrm{l}^{-1}$

D diffusion coefficient, $\mathrm{m}^{2} \mathrm{~s}^{-1}$

$\mathrm{D}_{\mathrm{ax}} \quad$ axial dispersion coefficient, $\mathrm{m}^{2} \mathrm{~s}^{-1}$ $\mathrm{d}_{\mathrm{t}} \quad$ tube diameter, $\mathrm{m}$

$\mathrm{E}$ exit age distribution function, $\mathrm{s}^{-1}$

$\mathrm{E}_{\theta} \quad$ normalized exit age distribution function

$F_{i} \quad$ molar flux of species i, mol s ${ }^{-1}$

ID internal diameter

L reactor length, $\mathrm{m}$

Q flow rate, $\mathrm{m}^{3} \mathrm{~s}-1$

$\mathrm{T}$ time, $\mathrm{s}$

$t_{d} \quad$ diffusion time, $s$

$\mathrm{t}_{\mathrm{m}} \quad$ micromixing time, $\mathrm{s}$

$t_{\text {res }} \quad$ mean residence time, $s$

$\mathrm{t}_{\mathrm{r}} \quad$ reaction time, $\mathrm{s}$

$\mathrm{u}$ linear flow rate, $\mathrm{m} . \mathrm{s}^{-1}$

$X_{s} \quad$ segregation index

Y selectivity of iodide

$\mathrm{Y}_{\mathrm{ST}} \quad$ selectivity of iodide in case of total segregation

$\Delta \mathrm{p} \quad$ pressure drop, $\mathrm{Pa}$

Greek Letters

$\begin{array}{ll}\mu & \text { dynamic viscosity, } \mathrm{Pa} \mathrm{s} \\ \mathcal{E} & \text { energy dissipation rate, } \mathrm{W} \mathrm{kg}^{-1} \\ \theta & \text { normalized time }\left(=\frac{t}{t_{m}}\right) \\ \theta_{0} & \text { break through time, } \mathrm{s} \\ \lambda & \text { absorption wavelength, } \mathrm{nm} \\ \nu & \text { kinematic viscosity, } \mathrm{m}^{2} \mathrm{~kg}^{-1} \\ \rho & \text { fluid density, } \mathrm{kg} \mathrm{m}^{-3} \\ \sigma & \text { standard deviation, } \mathrm{s}\end{array}$

Dimensionless groups

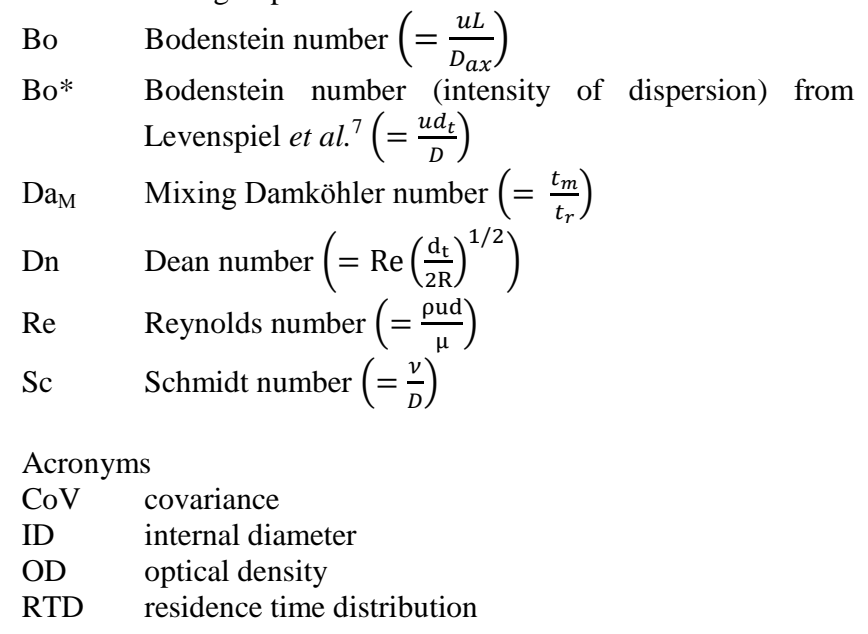

\section{REFERENCES}

1. Jensen, K. Microreaction engineering-is small better? Chemical Engineering Science, 2001 56, 293-303 (2001).

2. Hessel, V. Process windows - gate to maximizing process intensification via flow chemistry. Chemical Engineering and Technology 32, 1655-1681 (2009).

3. Hessel, V., Löwe, H. \& Schönfeld, F. Micromixers - A review on passive and active mixing principles. in Chemical Engineering Science 60, 2479-2501 (2005).

4. Nguyen, N. \& Wu, Z. Micromixers - a review. $J$. Micromechanics Microengineering 15, 1-16 (2005).

5. Watts, P. \& Wiles, C. Recent advances in synthetic micro reaction technology. Chem. Commun. 443-467 (2007). doi:10.1039/b609428g

6. Ehrfeld, W., Hessel, V. \& Löwe, H. Microreactors - New Technology for Modern Chemistry. Organic Process Research \& Development 5, (2001).

7. Levenspiel, O. Chemical reaction engineering. Chemical 
Bourne, J. R. Mixing and the selectivity of chemical reactions. Org. Process Res. Dev. 7, 471-508 (2003).

9. Roberge, B. D. M., Ducry, L., Bieler, N., Cretton, P. \& Zimmermann, B. Microreactor Technology: A Revolution for the Fine Chemical and Pharmaceutical Industries? (2005). doi:10.1002/ceat.200407128

10. Nagy, K. D., Shen, B., Jamison, T. F. \& Jensen, K. F. Mixing and dispersion in small-scale flow systems. Org. Process Res. Dev. 16, 976-981 (2012).

11. Atiemo-Obeng, V. A. \& Kresta, S. M. in Handbook of Industrial Mixing: Science and Practice 543-584 (2004). doi:10.1002/0471451452

12. Bošković, D. \& Loebbecke, S. Modelling of the residence time distribution in micromixers. Chem. Eng. J. 135, 138-146 (2007).

13. Lueth, F. G., Pauer, W. \& Moritz, H. U. Properties of smartscaled PTFE-tubular reactors for continuous emulsion polymerization reactions. Macromol. Symp. 333, 69-79 (2013).

14. Schwolow, S., Heikenwälder, B., Abahmane, L., Kockmann, N. \& Röder, T. Kinetic and Scale-up Investigations of a Michael Addition in Microreactors. Org. Process Res. Dev. 18, 15351544 (2014).

15. Aubin, J., Ferrando, M. \& Jiricny, V. Current methods for characterising mixing and flow in microchannels. Chem. Eng. Sci. 65, 2065-2093 (2010).

16. Guichardon, P. \& Falk, L. Characterisation of micromixing effciency by the iodide/iodate reaction system. Part I: experimental procedure. 55, 4233-4243 (2000).

17. Panić, S., Loebbecke, S., Tuercke, T., Antes, J. \& Bošković, D. Experimental approaches to a better understanding of mixing performance of microfluidic devices. Chem. Eng. J. 101, 409419 (2004).

18. Kölbl, A. \& Schmidt-Lehr, S. The iodide iodate reaction method: The choice of the acid. Chem. Eng. Sci. 65, 1897-1901 (2010).

19. Ehrfeld, W., Golbig, K., Hessel, V., Lowe, H. \& Richter, T. Characterization of mixing in micromixers by a test reaction: single mixing units and mixer arrays. Ind. Eng. Chem. Res 38, 1075-1082 (1999).

20. Kashid, M., Renken, A. \& Kiwi-Minsker, L. Mixing efficiency and energy consumption for five generic microchannel designs. Chem. Eng. J. 167, 436-443 (2011).

21. Guichardon, P., Falk, L. \& Villermaux, J. Characterisation of micromixing effciency by the iodide/iodate reaction system Part II : Kinetic Study. Chem. Eng. Sci. 55, 4233-4243 (2000).

22. Fournier, M.-C., Falk, L. \& Villermaux, J. A new parallel competing reaction system for assessing micromixing efficiency-Experimental approach. Chem. Eng. Sci. 51, 50535064 (1996).

23. Kölbl, A., Kraut, M. \& Schubert, K. The Iodide Iodate Method to Characterize Microstructured Mixing Devices. AIChE J. 54, 639-645 (2008)

24. Bourne, J. R. Comments on the iodide/iodate method for characterising micromixing. Chem. Eng. J. 140, 638-641 (2008).

25. Commenge, J. M. \& Falk, L. Villermaux-Dushman protocol for experimental characterization of micromixers. Chem. Eng. Process. Process Intensif. 50, 979-990 (2011).

26. Guo, X., Fan, Y. \& Luo, L. Mixing performance assessment of a multi-channel mini heat exchanger reactor with arborescent distributor and collector. Chem. Eng. J. 227, 116-127 (2013).

27. Fournier, M.-C., Falk, L. \& Villermaux, J. A new parallel competing reaction system for assessing micromixing efficiency-Determination of micromixing time by a simple mixing model. Chem. Eng. Sci. 51, 5187-5192 (1996).

28. Fang, J. Z. \& Lee, D. J. Micromixing efficiency in static mixer. Chem. Eng. Sci. 56, 3797-3802 (2001).

29. Rousseaux, J., Falk, L., Muhr, H. \& Plasari, E. Micromixing efficiency of a novel sliding-surface mixing device. AIChE $J$. 45, 2203-2213 (1999).

30. Ham, J.-H. \& Platzer, B. Semi-Empirical Equations for the Residence Time Distributions in Disperse Systems - Part 1:
Continuous Phase. Chem. Eng. Technol. 27, 1172-1178 (2004).

31. Pinot, J., Commenge, J.-M., Portha, J.-F. \& Falk, L. New protocol of the Villermaux-Dushman reaction system to characterize micromixing effect in viscous media. Chem. Eng. Sci. 118, 94-101 (2014).

32. Monnier, H., Wilhelm, a. M. \& Delmas, H. Effects of ultrasound on micromixing in flow cell. Chem. Eng. Sci. 55, 4009-4020 (2000).

33. Yang, K. et al. Micromixing Efficiency of Viscous Media in Micro-channel Reactor. Chinese J. Chem. Eng. 17, 546-551 (2009).

34. Yang, H. J., Chu, G. W., Zhang, J. W., Shen, Z. G. \& Chen, J. F. Micromixing efficiency in a rotating packed bed: Experiments and simulation. Ind. Eng. Chem. Res. 44, 7730-7737 (2005).

35. Ananthakrishnan, V., Gill, W. N. \& Barduhn, A. J. Laminar dispersion in capillaries: Part I. Mathematical analysis. AIChE J. 11, 1063-1072 (1965).

36. Taylor, G. Dispersion of Soluble Matter in Solvent Flowing Slowly through a Tube. Proceedings of the Royal Society A: Mathematical, Physical and Engineering Sciences 219, 186-203 (1953).

37. Janssen, L. A. M. Axial dispersion in laminar flow through coiled tubes. Chem. Eng. Sci. 31, 215-218 (1976).

38. Moulin, P., Veyret, D. \& Charbit, F. Dean vortices: comparison of numerical simulation of shear stress and improvement of mass transfer in membrane processes at low permeation fluxes. J. Memb. Sci. 183, 149-162 (2001).

39. Bothe, D., Stemich, C. \& Warnecke, H. Fluid mixing in a Tshaped micro-mixer. 61, 2950-2958 (2006).

40. Soleymani, A., Yousefi, H. \& Turunen, I. Dimensionless number for identification of flow patterns inside a $\mathrm{T}$ micromixer. Chem. Eng. Sci. 63, 5291-5297 (2008).

41. Wiles, C. Application Note 15: The Scale-up of (Z)-Ethyl-2cyano-3-phenylacrylate Synthesis-From Labtrix ${ }^{\circledR}$-S1 Parameter Screening to KiloFlow ${ }^{\circledR}$ Production. $1-8$ (2012). at <www.chemtrix.com>

42. Scharratt, N., P. Handbook of Batch Process Design. (Blackie, 1997).

43. Jiao, W., Liu, Y. \& Qi, G. Micromixing Efficiency of Viscous Media in Novel Impinging Stream- Rotating Packed Bed Reactor. (2012)

44. Su, Y., Chen, G. \& Yuan, Q. Ideal micromixing performance in packed microchannels. Chem. Eng. Sci. 66, 2912-2919 (2011).

45. Streiff, F. A. \& Rogers, J. A. Don't overlook static-mixer reactors. Chem. Eng. (New York) 101, 78-82 (1994). 